from the fact that valuable food plants spread so rapidly that their origin becomes obscuredespecially cereals. Maize, to give one example, indigenous to America and unknown in the old World before Columbus, became the staple food of half Africa within a century of the discovery, spreading from tribe to tribe, far beyond European exploration. In Europe it penetrated to the Levant, and became known in France as blé de Turquie. In Germany it was called türkische Weisen. In England it was called guinea corn, because it came to us from West Africa. I suggest that there is a splendid opportunity for a young man, trained in botany, to undertake the revision of that fine work "The Origin of Cultivated Plants" written by Alphonse de Candolle. The last edition of this was published in 1909, but the preface, written in 1882 , is a model of sympathetic guidance to those who follow. Much has been discovered since de Candolle's day, and a new edition is badly needed. I hope that some of the younger men may take up the task.

\title{
A Marsupial Sabre-toothed Tiger from South America*
}

$\mathrm{T}$ HE marsupial or pouched mammals of Australia are well known to include groups which are parallel in form and habits to many groups of the higher mammals living in the rest of the world. The pouched mammals of South America, both past and present, are less varied and represent only insect-eaters and flesh-eaters. Among the latter, however, Dr. Elmer S. Riggs has just described perhaps the most remarkable mimic of a higher mammal hitherto discovered. In a Pliocene deposit in Catamarca, northern

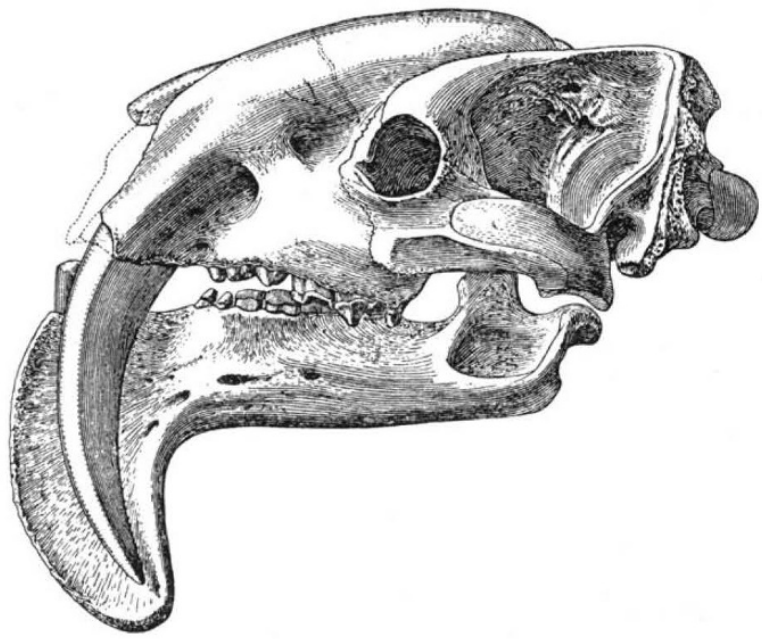

FIG. 1. Side view of skull of Thylacosmilus atrox. Holotype No. P 14531 Field Museum. Roproduced from Field Mus. Geol. Ser. 6, 61, Dec. 11, 1933.

Argentina, he has found the remains of a pouched mammal which nearly resembles the familiar Machærodonts or 'sabre-toothed tigers', but is clearly inferior in the less efficient adaptations of its skeleton to its mode of life.

Of Thylacosmilus, as Dr. Riggs names the new mammal, most parts of the skeleton are now in the Field Museum of Natural History, Chicago. The skull, which is shown in side view in Fig. 1, measures from 8 to 10 inches in length, according

* Elmer S. Riggs, "A new Marsupial Saber-tooth from the Pliocene of Argentina, and its Relationships to other South American Predacious Marsupials" (Trans. Amer. Phil. Soc., -n.s., 24, pt. 1; 1934). to the species; and the head and trunk would have about the same relative proportions as in a leopard. The great canine tusks differ from those of the ordinary sabre-tooths in having an open pulp-cavity enabling them to grow throughout life; and the maxillary bones which enclose their roots grow upwards and backwards over the forehead to accommodate them. These tusks are not quite sabre-shaped, being flattened triangular in section, and the enamel which only incompletely covers them is very thin. They are very feebly and finely serrated on the edge. There are no incisor teeth, and the molars and premolars are as small and inefficient for cutting flesh as those of their contemporary relatives, the Borhyænidævery different from the powerful corresponding teeth of the true sabre-tooths. There is a bony postorbital bar, evidently to strengthen the side of the skull ; and the back of the head is shaped for the insertion of strong neck-muscles. The lower jaw is remarkable for the large size of the pair of bony flanges which protect the tips of the canine tusks. They are larger than those in any of the sabre-tooths.

The hinge of the lower jaw on the skull, however, is almost exactly as in the sabre-tooths, and the mouth could be opened as widely as in them to allow the tips of the tusks to be used. The neck vertebræ are large and strong for the origin of the powerful neck muscles which would be needed for the thrusting of the tusks. The feet, however, are astonishingly different from those of the sabretooths, for they bear only pointed toes, not grasping claws.

As Dr. Riggs points out, the discovery of Thylacosmilus is all the more remarkable because among the numerous fossil mammals known from the older Tertiary rocks of Argentina there are no recognisable ancestors in which the canines are gradually enlarging. It shows that the deposits hitherto explored contain only an imperfect record of the extinct mammal fauna, and that much may be expected from future discoveries. A. S. W. 